\title{
PROMOÇÃO dO ALEITAMENTO MATERNO: PRÁtICAS DE MÉdICOS E ENFERMEIROS DA ATENÇÃo PRIMÁRIA À SAÚDE
}

\section{PROMOTION OF BREASTFEEDING: PRACTICES OF PHYSICIANS AND NURSES OF PRIMARY HEALTH CARE}

\section{PROMOCIÓN DE LA LACTANCIA MATERNA: PRÁCTICAS DE MÉDICOS Y ENFERMEROS DE LA ATENCIÓN PRIMARIA DE SALUD}

Rosane Meire Munhak da Silva ${ }^{1}$, Andrea Ferreira Ouchi França ${ }^{2}$, Ana Paula Contiero Toninato ${ }^{3}$, Rosangela Aparecida Pimenta Ferrari $^{4}$, Sebastião Caldeira ${ }^{5}$, Adriana Zilly ${ }^{6}$

\section{RESUMO}

Objetivo: Apreender o conhecimento e práticas de médicos e enfermeiros para promover o aleitamento materno, após a implementação da Rede Mãe Paranaense. Método: Pesquisa qualitativa, com análise baseada na Fenomenologia Social. Realizaram entrevistas com 35 médicos e 27 enfermeiros atuantes no serviço de atenção primária. Resultados: Os profissionais possuem pouco conhecimento sobre a adesão do aleitamento materno em seus municípios. Suas ações foram pontuais, ocorrendo em algum momento específico do pré-natal, puerpério ou puericultura, sendo realizadas orientações individuais ou palestras. Entretanto, os profissionais esperam que a promoção do aleitamento materno possa reduzir a mortalidade infantil. Considerações finais: $O$ desconhecimento da baixa adesão e a fragmentação das práticas, para promover o aleitamento materno, fragilizam o planejamento de ações integrais para transformar os indicadores de saúde infantil.

Descritores: Aleitamento materno; Promoção da saúde; Médicos; Enfermeiros; Atenção Primária à Saúde.

\section{ABSTRACT}

Objective: To analyze the knowledge and practices developed by physicians and nurses to promote breastfeeding after the "Mãe Paranaense Network" implementation. Method: A qualitative research with analysis based on Social Phenomenology was used. Interviews were conducted with 35 physicians and 27 nurses that work in primary health services. Results: The professionals have little knowledge about breastfeeding adherence in their municipality. Their actions were punctual, occurring at some specific time of prenatal, puerperal or childcare, with individual orientations or lectures. However, the professionals hope that promoting breastfeeding can reduce child mortality. Final considerations: The lack of knowledge about low adherence and fragmentation of practices to promote breastfeeding weaken the planning of integral actions to transform child health indicators.

Descriptors: Breast Feeding; Health Promotion; Physicians; Nurses; Primary Health Care.

\section{RESUMEN}

Objetivo: Apreciar el conocimiento y las prácticas de los médicos y enfermeros para promover la lactancia materna después de la implementación de la Red Madre Paranaense. Método: Investigación cualitativa, con análisis basado en la Fenomenología Social. Se realizaron entrevistas con 35 médicos y 27 enfermeros que están actuando en el servicio de atención primaria. Resultados: Los profesionales tienen poco conocimiento sobre la adherencia a la lactancia materna en sus municipios. Sus acciones fueron puntuales, ocurriendo en algún momento específico del prenatal, puerperio o puericultura, siendo realizadas orientaciones individuales o charlas. Sin embargo, los profesionales esperan que la promoción de la lactancia materna pueda reducir la mortalidad infantil. Consideraciones finales: El desconocimiento sobre la baja adherencia y fragmentación de las prácticas para la promoción de la lactancia materna debilitan la planificación de acciones integrales para transformar los indicadores de salud infantil.

Descriptores: Lactancia Materna; Promoción de la Salud; Médicos; Enfermeros; Atención Primaria de Salud.

Doutora em Enfermagem em Saúde Pública na EERP/USP e docente na Universidade Estadual do Oeste do Paraná ${ }^{\text {; }}$ Docente da Universidade Estadual do Oeste do Paraná ; Doutora em Enfermagem em Saúde Pública na EERP/USP e Enfermeira na Universidade Estadual do Oeste do Paraná ${ }^{3}$; Doutora em Enfermagem em Saúde Pública pela EERP/USP e docente na Universidade Estadual de Londrina ${ }^{4}$; Graduado em Enfermagem. Doutor em Ciências pela Universidade de São Paulo. Docente na Universidade Estadual do Oeste do Paraná ${ }^{5}$; Doutora em Ciências Biológicas pela Universidade Estadual de Maringá e docente da Universidade Estadual do Oeste do Paraná ${ }^{5}$.

Como citar este artigo:

Silva RMM, Caldeira S, Toninato APC, et al. Promoção do aleitamento materno: práticas de médicos e enfermeiros da atenção primária à saúde. Revista de Enfermagem do Centro-Oeste Mineiro. 2019;9:e3335. [Access http://dx.doi.org/10.19175/recom.v9i0.3335 ; Disponível em: . DOI: 


\section{INTRODUÇÃO}

Práticas adequadas de aleitamento materno contribuem, de forma significativa, para a redução da mortalidade infantil. Sabe-se que $87 \%$ das mortes ocorridas em crianças menores de seis meses poderiam ser evitadas e estas estão fortemente associadas à maior prevalência de aleitamento materno exclusivo ${ }^{(1-2)}$.

O aleitamento materno proporciona inúmeras vantagens para as crianças, mães e família. É primordial para o crescimento físico infantil, desenvolvimento psicológico e funcionamento imunológico, principalmente durante o primeiro ano de vida, pois protege contra doenças infecciosas, má oclusão dental e doenças crônicas como diabetes e sobrepeso, além disso acende o vínculo entre a mãe e a criança proporcionando o fomento ao amor, proteção e aconchego ${ }^{(3-4)}$.

Mesmo diante dos progressos tecnológicos das fórmulas lácteas e alimentos para as crianças, em especial nos primeiros seis meses de vida, o leite materno continua unânime como alimento ideal, pois contempla devidamente as necessidades metabólicas dos lactentes, além de impactar positivamente na contenção de gastos da família ${ }^{(5)}$.

A Organização Mundial da Saúde recomenda que nos primeiros seis meses de vida a criança receba aleitamento materno exclusivo, contudo, em nível mundial, a prevalência, nessa idade, não atinge $40 \%$ das crianças, o que se repete no Brasil: $41 \%$. Um dos objetivos preconizados pela Organização Mundial de Saúde, para 2025, é o aumento da taxa global em, pelo menos, $50 \%$ de aleitamento materno exclusivo até os seis meses de idade ${ }^{(6)}$.

Tendo em vista esse cenário, foi implementado, no estado do Paraná, em 2012, a Rede Mãe Paranaense, com o objetivo de reduzir os indicadores de mortalidade materno e infantil, por meio da atenção à saúde, de forma qualificada e segura na gestação, pós-parto e até dois anos de idade da criança. Uma das metas estratégicas do programa é melhorar a resolutividade na assistência pré-natal, parto, puerpério e puericultura, incluindo o incentivo ao aleitamento materno exclusivo, por meio da atuação das equipes de saúde da atenção primária ${ }^{(7)}$.

Tomando como referência o desafio relacionado ao desmame precoce e a implementação da Rede Mãe Paranaense, este estudo se justifica por buscar compreender se os profissionais de saúde, em especial médicos e enfermeiros, encontram-se preparados para assistir a díade mãe-filho, de acordo com as premissas da Rede. Diante dessa perspectiva, emergiu o seguinte questionamento: qual o conhecimento e as ações de médicos e enfermeiros para incentivar o aleitamento materno no serviço de atenção primária?

Para tanto, objetivou-se, neste estudo, apreender $o$ conhecimento e práticas desenvolvidas por médicos e enfermeiros, para promover o aleitamento materno, após a implementação da Rede Mãe Paranaense.

\section{MÉTODO}

Estudo de abordagem qualitativa tendo como eixo orientador as premissas conceituais e metodológicas da Fenomenologia Social de Alfred Schütz ${ }^{(8)}$. A Fenomenologia Social de Alfred Schütz visa a compreender o mundo social em seu significado intersubjetivo e tem como proposta a análise das relações sociais. Trata-se da estrutura de significados na vivência intersubjetiva da relação social face a face, voltando-se, portanto, para entender as ações sociais que têm um significado contextualizado, de configuração social ${ }^{(8)}$.

O estado do Paraná possui 22 Regionais de Saúde, com um total de 399 municípios. A Regional de Foz do Iguaçu (9) e a Regional de Cascavel (10a) localizam-se na região Oeste do estado do Paraná, enquanto a Regional de Londrina (17a), na região Norte. Este estudo foi desenvolvido em 21 municípios das três Regionais, dos quais: seis na Regional de Foz do Iguaçu, cinco de Cascavel e dez de Londrina. Salienta-se que, para a escolha dos municípios participantes, realizou-se sorteio entre os que pactuaram com a Rede.

Fizeram parte deste estudo 27 enfermeiros e 35 médicos. Utilizaram-se como critérios de inclusão: ser médico ou enfermeiro atuante nos municípios sorteados, ter mais de seis meses de atuação na atenção primária, realizar atendimento às gestantes e crianças. Foram excluídos os demais profissionais de saúde e os profissionais que não atuavam diretamente com o segmento materno-infantil.

Inicialmente, foram contactados os diretores das Regionais, para a autorização da pesquisa, assim como as secretarias de saúde de cada município. Posteriormente, realizou-se contato telefônico com os profissionais, propondo o encontro para esclarecer os 
propósitos da pesquisa. Os profissionais que foram contatados aceitaram participar e assinaram o Termo de Consentimento Livre e Esclarecido, não havendo recusa por parte de nenhum participante. A escolha dos profissionais participantes foi determinada, considerando sua atuação na unidade de saúde, com maior número de atendimentos médicos e de enfermagem à criança e à mulher, indicada pelo gestor de saúde do município.

A coleta de dados ocorreu entre outubro de 2014 e fevereiro de 2015, em dias e horários previamente agendados, durante a jornada de trabalho. Ressalta-se que as entrevistas foram realizadas em ambiente privativo, de forma individualizada, nas próprias salas ou consultórios de atendimento das unidades de saúde.

Para viabilizar a coleta de dados, foi utilizado um roteiro semiestruturado com base nas premissas e diretrizes da Rede, incluindo as questões: Como você percebe o aleitamento materno e sua adesão em seu município? Quais as ações que você realiza para promover o aleitamento materno? O que você espera para a saúde da criança? As entrevistas foram gravadas em áudio, ouvidas pelo pesquisador e participante para validação e, posteriormente, transcritas na íntegra.

A trajetória para a organização e análise dos dados aconteceu segundo os pressupostos da Fenomenologia Social ${ }^{(8-9)}$, ou seja, leitura criteriosa das entrevistas, agrupamento dos aspectos significativos para formar as categorias concretas e o mapa horizontal. Em seguida, iniciou-se a análise buscando compreender os "motivos por que" e os "motivos para", para finalmente organizar o grupo social composto por médicos e enfermeiros.

A Fenomenologia Social é um referencial com um olhar direcionado ao entendimento das ações dos seres humanos e suas possíveis relações sociais compostas de significados, o que justifica sua escolha para este estudo. Esse referencial permitiu compreender os fenômenos humanos em seu dia a dia a partir de experiências concretas, nesse caso, a vivência de médicos e enfermeiros na promoção do aleitamento materno ${ }^{(8)}$.

As categoriais identificadas foram: Percepção dos profissionais sobre o aleitamento materno e sua adesão; Ações de médicos e enfermeiros para promover o aleitamento materno; Aspectos que potencializam ou dificultam o aleitamento materno; e Perspectivas para a saúde da criança com o incentivo e apoio ao aleitamento materno.

Foram obedecidos todos os preceitos éticos e legais regulamentados pela resolução $n$ o 466/2012 do Conselho Nacional da Saúde. A pesquisa iniciou-se, após aprovação do projeto pelo Comitê de Ética em Pesquisa, envolvendo Seres Humanos da Universidade Estadual do Oeste do Paraná, sob o parecer $n^{\circ}$ 544.107. Para assegurar $O$ anonimato dos participantes, os enfermeiros foram identificados pela letra $E$, e os médicos pela letra $M$, com o número de entrevista sequencial, por exemplo, E1, E2, M1, M2 e, assim, consecutivamente.

\section{RESULTADOS E DISCUSSÃO}

O grupo formado pelos enfermeiros atuantes nos municípios das Regionais de Saúde estudadas tinha idade entre 24 e 48 anos e tempo de formação era de 3 a 24 anos. Já o grupo formado pelos médicos tinha idade entre 26 e 70 anos e tempo de formação de 1 a 41 anos.

As falas referentes ao conhecimento e ações desenvolvidas por médicos e enfermeiros, para incentivar 0 aleitamento materno, especificamente, após a implementação da Rede, foram apresentadas em categorias concretas do vivido. Assim, as categorias a seguir congregam, segundo Alfred Schütz ${ }^{(8)}$, os "motivos por que", que envolvem toda a bagagem de conhecimentos profissional, e os "motivos para", isto é, suas expectativas para a saúde da criança com as ações para promoção do aleitamento materno.

\section{Percepção dos profissionais sobre o aleitamento materno e sua adesão}

Ao serem questionados sobre como percebem o aleitamento materno e sua adesão na área de abrangência da unidade de saúde do município de atuação, os participantes responderam: "Nós não temos problemas quanto a isso, isso já está sendo uma busca natural da gestante. Elas já estão amamentando seus bebês tranquilamente, muito [ênfase] raramente a gente perde um seio (M3)". "Isso a gente tem batido assim muito, mas por outro lado, a adesão também é muito grande, quase que 100\%" (M5). "Me falaram que o índice não era tão ruim não (...), o exclusivo seis meses não é tanto assim não (...) não tem estatística não, mas não é tanto (...)" (M21). "Olha, exclusivo, eu acho, assim avaliando (...) tirando pela puericultura no início, na 
puericultura até os seis meses, é uns $85 \%(\ldots)^{\prime \prime}$ (E17).

A bagagem de conhecimentos relatada pelos profissionais estudados, diz respeito à experiência vivenciada no atendimento materno e infantil, no que tange ao aleitamento materno ou, por meio dos relatos que ouviram de outros profissionais. Assim, ao serem questionados sobre a incidência do aleitamento materno, em seu município, os médicos e os enfermeiros entrevistados, trouxeram sua bagagem de conhecimento herdada dos predecessores, adquirida na vivência do atendimento materno e infantil como algo que se pode acrescentar à própria experiência vivida. Essa experiência só pode ser compreendida, por meio de ações exteriorizadas que constituem a base da comunicação e da relação social, especialmente na relação do tipo face a face entre a equipe de saúde, a mulher e a criança que amamenta ${ }^{(8)}$.

Nesse sentido, a maioria dos profissionais descreveu a grande adesão de aleitamento materno, em sua realidade, no entanto, não afirmaram de forma concreta tal prevalência, principalmente ao mencionarem que acreditam ou que alguém havia dito que é alta, deixando explícita que a bagagem de conhecimentos pode ser advinda de várias formas, não mostrando conhecimento suficiente sobre a alta ou a baixa adesão.

Importante destacar que, ao referir a grande adesão do aleitamento materno nos serviços de saúde do município de sua atuação, os profissionais participantes podem ter mascarado a sua experiência para mostrar o que consideram correto ou ideal no contexto investigado.

Estudos realizados em municípios brasileiros descrevem que a prevalência do aleitamento materno exclusivo nos seis primeiros meses de vida da criança tem sido baixa, entre $34,1 \%$ a $37 \%{ }^{(9-10)}$. Nessas perspectivas, as afirmações dos entrevistados não parecem verossímeis no contexto brasileiro e que, portanto, podem indicar desconhecimento da real prevalência do aleitamento materno em sua região. Tais aspectos podem fragilizar as ações de promoção, pois, embora se verifique que o aleitamento materno exclusivo encontra-se em ascensão no Brasil, ainda existem lacunas no que diz respeito à adesão do aleitamento materno exclusivo até o sexto mês e de forma complementar até o segundo ano de vida.
Ademais, conforme dispõe a linha guia da Rede Mãe Paranaense, é fundamental conhecer os possíveis fatores de risco para a mortalidade infantil, como exemplos, a falta do aleitamento materno exclusivo até o sexto mês, assim como o desmame precoce, os quais são considerados essenciais para orientar o planejamento das ações e para transformar indicadores que desfavorecem à saúde materna e infantil ${ }^{(7)}$.

A experiência do aleitamento materno, vivenciada pelos profissionais pesquisados e pela mulher que amamenta, se dá no cotidiano vivido desses atores sociais, ou seja, no mundo da vida, que, para Schütz, é um mundo cultural e intersubjetivo. $O$ atendimento quando envolve $o$ aleitamento materno, ocorre como um processo interativo que, ao ser vivenciado por duas ou mais pessoas, possui significado para os envolvidos nessa ação social. Assim, a mulher que amamenta e os profissionais da saúde possuem interesses que lhes são próprios e que os motivam e direcionam para as ações de cuidado. São os motivos existenciais - motivação ${ }^{(8)}$.

\section{Ações de médicos e enfermeiros para a promoção do aleitamento materno}

Os profissionais, nessa categoria, relataram como são realizadas as ações de promoção do aleitamento materno, assim como o momento em que tais ações são desenvolvidas.

Durante a gestação, as ações envolveram orientações individuais nas consultas de pré-natal e realização de palestras para grupos de gestantes. Tais ações foram complementadas com visitas domiciliares e com a participação do banco de leite humano. Os relatos, a seguir, evidenciam o exposto: “(...) acontece durante as consultas de pré-natal, mas é mais trabalhado no grupo de gestante, onde temos a colaboração do banco de leite na unidade" (M8). "As orientações são feitas individualmente, a gente não tem grupo de gestantes (...)" (E2). "Então, a gente faz os encontros das gestantes, todo mês, cada profissional vai lá faz orientações" (...) (E6).

(...) "quando ela vem pra fazer a primeira consulta de pré-natal, (...) a gente já avalia as mamas, os mamilos e explica sobre a pega da criança" (E8). "Realizo palestra e faço grupo de gestantes quando possível e também faço orientação na visita domiciliar" (E25).

As ações citadas pelos profissionais como estratégia de promoção ao aleitamento demonstram abordagens como: orientações em grupos; palestras, para realização de educação 
em saúde. A mulher que amamenta, o enfermeiro e o médico, no momento do atendimento e do cuidado vivenciam uma relação social que se dá no mesmo espaço e tempo cronológico. Essa relação ocorre na interação da relação face a face ${ }^{(8)}$. Dessa forma, a relação social face a face é permeada de interesses comuns para o desenvolvimento das ações de cuidado. É o que Schütz denomina reciprocidade de intenção no que concerne ao ensino e a aprendizagem.

Nesse sentido, a literatura científica descreve estratégias para a educação em saúde que podem ser incorporadas, para além das citadas pelos profissionais, com espaço para construção do conhecimento sobre aleitamento materno, rodas de conversas pontuando as necessidades individuais, assim como o uso de ferramentas tecnológicas, como as redes sociais ou aplicativos de celulares, que poderiam facilitar a comunicação entre profissionais e a gestante ${ }^{(11)}$.

É importante o desenvolvimento de ações educativas amparadas no conhecimento científico e centradas no saber dialógico, para nortear as práticas de promoção do aleitamento materno, adotando como estratégias propostas pedagógicas mais ativas com base na educação crítica reflexiva, no contexto de todos os atores envolvidos ${ }^{(11)}$. Na relação de cuidado de saúde materno e infantil, é preciso reconhecer as necessidades de saúde da mulher e da criança e identificar quais as ações de saúde estas requerem, quer sejam, na puericultura, no aleitamento materno ou no cuidado à mulher. Assim, faz-se necessário que a mulher nutriz, e os profissionais que prestam atendimento, seja o enfermeiro, o médico ou outro, possam ser capazes de resgatar suas vivências e seu percurso existencial, sendo esse resgate sobre o que Schütz denomina de situação biográfica. A situação biográfica permite aos atores sociais interpretar o mundo, a partir do acervo de experiências e de conhecimentos prévios, tornando-os capazes de refletir e de compreender as suas ações e a sua relação com o mundo ${ }^{(8-9)}$.

Para ampliar as ações de educação em saúde já desenvolvidas, os profissionais podem criar momentos para a promoção da escuta ativa ou qualificada, bem como, atitude compreensiva, proporcionando à mulher a oportunidade de expressar seu saber, proveniente do convívio com outras mulheres, família e comunidade, para que ela assuma com mais segurança a prática de amamentar. A escuta ativa ou qualificada deve ocorrer por meio da relação face a face entre o profissional da saúde e a mulher que amamenta. Nesse contexto, a fenomenologia social permite que ambos, mães e profissionais, tenham intenções recíprocas em prol do aleitamento ${ }^{(8-9)}$. $\mathrm{Na}$ promoção da amamentação, as trocas de experiências, opiniões, dúvidas, sentimentos, são necessários, pois favorecem a construção do conhecimento $^{(11)}$.

Com respeito às ações para incentivar o aleitamento materno no puerpério, médicos e enfermeiros destacaram a importância destas serem iniciadas ainda na maternidade. "Especificamente no hospital X, a tentativa de vincular, de fazer com que a puérpera sinta a necessidade de amamentar, é muito intensa, forte, eu acho que bem adequada" (M1).

Destacaram, inclusive, a importância de aproveitar o momento da vacinação, da revisão puerperal e da própria puericultura. "No puerpério, a gente vai reforçando bastante, pergunta como que está, examina a mama, vê se está tudo certo, aí assim a gente dá mais atenção" (M23). "O incentivo ocorre por meio da primeira consulta da mãe, quando ela traz para a vacina da $B G C$, então a gente aproveita esse momento para orientá-la” (E3). “(...) a gente faz as orientações na primeira puericultura (...)" (E19).

O sucesso para as práticas do aleitamento materno envolvem ações e atividades individualizadas ou coletivas direcionadas às gestantes, durante todo o pré-natal com extensão nas puericulturas, por meio de informes da magnitude, vantagens, benefícios e dificuldades que envolvem essa prática. Ademais, o preparo psicológico e fisiológico da mãe, o saber de como cuidar das mamas e o posicionamento dela e da criança no ato de amamentar, ou seja, a demonstração das técnicas de amamentação são fundamentais para o êxito da lactação( ${ }^{(5)}$.

Tais ações foram reforçadas pelos Agentes Comunitários de Saúde e enfermeiros, durante as visitas domiciliares. “(...) existe visitas de agentes comunitários e enfermeira, estimulando o aleitamento evitando também o abandono do aleitamento materno antes do sexto mês de vida" (M26). “(...) as agentes comunitárias de saúde vai lá faz visitas (...), senta com a gestante, orienta, ensina, coloca o bebê na posição correta para amamentar (...)" (E6). 
A Rede Mãe Paranaense recomenda que a equipe da atenção primária de saúde realize visita domiciliar para as puérperas e recémnascido até o quinto dia após alta hospitalar, com a finalidade de avaliar a amamentação, se apresentam dificuldades, esclarecer dúvidas, apoiar e incentivar o aleitamento materno, de acordo com as necessidades da díade mãefilho ${ }^{(7)}$.

Dessa forma, percebe-se aquilo que é feito, bem como, aquilo que é recomendado ou preconizado no que tange ao aleitamento materno. Nesse sentido, os relatos trazem as experiências vividas e as expectativas, visto que a bagagem de conhecimento é algo herdado dos predecessores, dos contemporâneos, aquilo que podemos acrescentar à nossa própria experiência vivida por meio das ações e da relação social face a face. Essas ações são impulsionadas pelos "motivos por que" e pelos "motivos para". Os "motivos por que" são razões enraizadas em experiências passadas que dizem respeito aos atos concretizados, sendo possível reconstruir esses motivos em retrospectiva. Já a orientação para o comportamento futuro constitui-se no "motivo para", que é uma categoria essencialmente subjetiva, pois ainda não aconteceu $^{(8-9)}$.

Muito embora se observe que algumas ações de incentivo e apoio ao aleitamento estão acontecendo, ainda que em algum período do pré-natal ou no puerpério, há de desvelar caminhos que possibilitem que essas ações aconteçam de forma integral, ou seja, planejadas de forma que contemplem a assistência, durante o pré-natal, parto, puerpério e seguimento da criança, como descreveu a fala de um profissional: “(...) desde o pré-natal é feito um trabalho. (...) as enfermeiras fazem uma entrevista é feita essa abordagem da importância do aleitamento materno. No próprio hospital, é feito um trabalho em cima dessa gestante pra que ela logo nas primeiras horas coloque essa criança para sugar. Depois que essa criança nasce (...) a gente faz uma reunião toda sexta-feira, a gente tem uma nutricionista que faz uma abordagem muito grande (...) depois passa para as mães a importância do aleitamento materno nos atendimentos de puericultura também. Então a gente faz um trabalho de incentivo bem grande para que essa mãe não perca o benefício do aleitamento materno" (M29).

\section{Aspectos que potencializam ou dificultam o aleitamento materno}

Essa categoria também descreveu os "motivos por que" e transcreveu a realidade vivenciada por médicos e enfermeiros relacionada aos aspectos que potencializam ou dificultam o aleitamento materno.

O primeiro aspecto que os profissionais descreveram como potencializador do aleitamento se referiu à conscientização das mães: “(...) é necessário comentar antes da mulher ganhar o bebê, (...) porque, muitas vezes, a mãe não tem conhecimento, por isso não dão aleitamento materno" (...) (M11). "As mães têm notado que as crianças amamentadas, elas são muito mais saudáveis e tem muito menos problemas digestivos e, principalmente, respiratórios" (M14). "Eu acho que melhorou muito. As mães estão mais conscientes. Elas têm um maior esforço. Mas eu noto que é mais uma opção da mãe" (M20).

É primordial que as mães recebam orientação sobre o aleitamento a partir da primeira consulta do pré-natal, com incentivo e informações, a fim de que construam um conhecimento necessário para adesão. Estudos apontam que as mães têm ciência que o leite materno é essencial e seguro para o bebê, pois se refere a uma fonte de proteção que atua na preservação contra doenças e redução da mortalidade infantil ${ }^{(13-14)}$.

Outro fator descrito como potencializador, pelos profissionais, referiu-se ao aumento do tempo da licença maternidade: "As mães têm hoje em dia um tempo maior para ficar junto com os bebês (...). Que se está aumentando, geralmente de quatro para seis meses, que elas ficam sem trabalhar" (...) (M14).

A licença maternidade influencia, de forma positiva, a prevalência do aleitamento. Estudo descreve que a duração da licença maternidade está fortemente relacionada com o tempo da amamentação, seus benefícios relacionados e a diminuição da mortalidade infantil. O Brasil se sobressai em nível internacional, por oferecer maior tempo de afastamento em semanas e percentual de salário pago à mulher em licença maternidade, ocupando o sétimo lugar no ranking de 202 países pesquisados. Contudo, são indispensáveis evoluções no que diz respeito ao tempo de licença, considerando a premissa de manter o aleitamento materno exclusivo até o sexto mês de vida ${ }^{(15)}$. 
Como último aspecto que potencializou o aleitamento materno, os profissionais destacaram estratégias desenvolvidas de forma individual ou em parceria com a secretaria de saúde do município: “(...) pessoas da secretaria de saúde vão visitar as pacientes no hospital enquanto elas estão internadas (...) a pessoa recebe uma visita e uma orientação lá sobre o aleitamento (...)" (M15). "A gente também tem um questionário que a gente preenche mensalmente de todas as crianças que fazem puericultura (...) a gente ainda preenche para saber se estas crianças estão em aleitamento materno exclusivo, as que estão no predominante, complementar e as que não estão em aleitamento materno (...)" (E21).

$\mathrm{Na}$ experiência dos profissionais, as estratégias convencionais, como aconselhamento, visitas domiciliares, orientações e informações foram comumente usadas para a sensibilização em relação à lactação, podendo ser realizada de forma individual ou em grupos. Além desses métodos tradicionais, têm surgido parcerias e inovações como a elaboração de materiais didáticos, manuais ilustrativos referentes à temática, as quais têm se destacado como táticas potencializadoras no incentivo ao aleitamento, uma vez que esclarece incertezas rotineiras a respeito desse tema ${ }^{(16)}$. Para além das técnicas de ensino e aprendizagem, é preciso também chegar à subjetividade ${ }^{(8)}$ dessas mulheres no tocante ao desejo e a importância do amamentar por si e para o seu filho.

Por meio da Rede Mãe Paranaense, a Secretaria da Saúde do Estado do Paraná, em parceria com as Regionais de Saúde do Estado, buscam desenvolver ações e estratégias usuais e educativas com vistas a assegurar o sucesso do aleitamento materno ${ }^{(7)}$.

Todavia, inúmeras dificuldades foram apresentadas pelos profissionais para a manutenção do aleitamento materno, tais como: o retorno ao trabalho, as questões culturais e a falta de conscientização da própria equipe de saúde.

Sobre o retorno ao trabalho como um aspecto complicador, os profissionais relataram: "Volto a falar, a dificuldade é quando a mãe retorna ao trabalho, ela não consegue fazer aquela amamentação de pelo menos seis meses e tem que entrar com outros leites, e a gente vai orientando como fazer" (M5). "Quando elas têm que trabalhar, vê bastante que elas não tem esse pique de tirar leite, congelar, guardar. As empresas não facilitam, as licenças de quatro meses atrapalham muito" (E16). "Chegou uma mãe aqui, faz uns 15 dias, mas chorava tanto (...). Porque ela ia voltar para o trabalho e não queria dar outro leite para o bebê (...)" (E20).

Os profissionais participantes visualizam o desafio das puérperas para a continuidade da amamentação ao retornarem ao trabalho após a licença maternidade. Tal fato dificulta o aleitamento materno exclusivo, uma vez que o afastamento materno do lar obstaculiza a realização da aleitação. As mães que ficam mais em casa após o nascimento dos filhos amamentam mais ${ }^{(13)}$. Mesmo diante desse amplo obstáculo, a Rede apresenta como competência da equipe de saúde o incentivo ao aleitamento materno exclusivo ${ }^{(7)}$.

Sobre as questões culturais interferindo no aleitamento materno, os profissionais relatam algumas dificuldades: "Nós temos um câncer no estado, que se chama leite do governo. Então, as mães tem na cabeça, por uma questão política lá do passado, eleitoreira, que fez muita propaganda, que esse leite do governo era fantástico. Que era um leite forte, com vitaminas, isso e aquilo. Então as mães chegam pra gente com 2, 3 meses doidas pra dar o famoso leite do governo" (M22). "Ah, é assim, tem muita questão cultural, é, a questão do aleitamento materno acho que é uma coisa que a gente não vai mudar" (...) (E8). "Tem muitos paradigmas em relação a amamentação, (...) o seio vai cair, ai isso ai aquilo. (...) principalmente em cidade pequena o pessoal é bem humilde, essas crenças existem (...)" (E11).

A amamentação não é uma ação unicamente instintiva, mas é um ato fortemente persuadido pela experiência da mãe, a partir de sua bagagem de conhecimento ${ }^{(8)}$, pelo contexto vivido por esse grupo social, além dos mitos e crenças que podem interferir diretamente nesse processo. Estudo realizado no estado de Missouri, Estados Unidos, indicou que conhecer alguém que amamentou tem sido associado a experiências positivas no processo de aleitamento materno, especialmente em populações mais vulneráveis ${ }^{(17)}$.

O cuidado, assim como o aleitamento materno, como uma das formas de cuidar, é uma experiência vivenciada de modo natural e constitui-se, na primeira relação social do ser humano $^{(8)}$. É um processo interativo que, ao ser vivenciado por duas ou mais pessoas, possui significado para os envolvidos nessa ação social. Assim, a mulher que amamenta o bebê, ou seja, a 
díade mãe e filho e os profissionais que cuidam dessa díade, possuem interesses que lhes são próprios e que os motivam e direcionam para as ações de cuidado. São os motivos existenciais, também denominados motivação.

Nesse mesmo pensar, faz-se necessário que os profissionais que prestam atendimento, no caso deste estudo, o enfermeiro e o médico, bem como, a mulher que amamenta, sejam capazes de resgatar suas vivências, permeado pela bagagem de conhecimentos de cada um, perfazendo a situação biográfica ${ }^{(8)}$. Nesse sentido, durante a vivência de cuidado de saúde, o enfermeiro, o médico e a mulher que amamenta, adquirem experiências que constituem a tipificação, aquilo que é típico para cada um. O mundo cotidiano apresenta-se nas tipificações, ou seja, nas representações construídas pelos próprios atores sociais, de acordo com suas experiências e relevâncias ${ }^{(8)}$.

Assim, evidencia-se a necessidade de que os profissionais de saúde compreendam o contexto sociocultural, experiências, as incertezas, medos e perspectivas das mães, bem como desmistifiquem os conceitos que impactam negativamente no aleitamento materno.

Referente à fala do profissional sobre o "leite do governo", pontua-se que, em 2003, no Estado do Paraná, foi lançado o Programa Leite das Crianças cujo objetivo é colaborar na redução da deficiência nutricional infantil, através da distribuição de um litro de leite pasteurizado enriquecido com vitaminas " $A$, " $D$ " e ferro quelato, por dia, para crianças, na faixa etária entre 6 e 36 meses $^{(18)}$. A oferta de leite desse Programa pode interferir na continuidade do aleitamento materno e também se opõe à contraindicação do leite de vaca na forma integral em crianças menores de 12 meses, devido principalmente, ao seu potencial alergênico e conteúdo proteico. Desse modo, tem sido recomendada uma reavaliação da faixa etária das crianças beneficiadas pelo Programa de 6 a 36 meses, para 12 a 36 meses $^{(19)}$.

As divergências entre a equipe de saúde para incentivar e apoiar o aleitamento materno também foi apontada nos discursos dos profissionais: "O nosso complicador, ás vezes é o pediatra (...). Ele passa fórmula e fala: 'Ah, está dando muito o peito, o que é isso, pode parar" (E19).

Boas experiências para o incentivo e promoção do aleitamento precisam ser construídas com a conscientização e comprometimento da equipe de saúde. A equipe de saúde necessita estar adequadamente capacitada e consciente para oportunizar as lactantes orientações apropriadas do processo de lactação e, dessa forma, viabilizar e auxiliar na promoção do aleitamento ${ }^{(16)}$.

É necessário enfatizar, na qualificação dos profissionais de saúde, os valores culturais que defendam a amamentação, favorecendo o seu envolvimento neste processo. O profissional precisa estar sensibilizado, quanto à importância do aleitamento, para saber reconhecer as necessidades da mulher, em todas as fases do ciclo gravídico puerperal, para poder contribuir com o sucesso da amamentação ${ }^{(20)}$.

\section{Perspectivas para a saúde da criança com o incentivo e apoio ao aleitamento materno}

Nessa categoria, foi possível identificar os "motivos para" dos profissionais em relação às suas perspectivas para a saúde da criança com o incentivo e apoio ao aleitamento materno, conforme o exposto em seus relatos: "Espero que as crianças sejam mais assistidas, diminua a mortalidade infantil que eu vi que diminuiu" (M18). “(...) o que a gente imagina é que possa reduzir a mortalidade infantil, (...) reduzir as morbimortalidades (...) de uma forma geral" (M28). “(...) redução nas internações, nas doenças e melhora da nutrição e crescimento. (...) uma assistência de qualidade pra criança também, (...) e um menor risco de doenças, de morte. Eu acho que esse é o objetivo assim, o mesmo da Rede Mãe Paranaense" (E18).

Para Alfred Schütz ${ }^{(8)}$, toda bagagem de conhecimentos, molda a situação biográfica de cada um, bem como, o torna capaz de projetar-se em expectativas ou perspectivas. Assim, nos relatos dos participantes deste estudo, os profissionais, em sua maioria, descreveram a redução da mortalidade infantil como principal perspectiva para à saúde da criança, a partir da promoção do aleitamento materno. Ressalta-se que a Rede tem como maior proposta, para o conjunto de suas ações, a redução da mortalidade infantil ${ }^{(7)}$.

De fato, a promoção do aleitamento materno implica, diretamente, na proteção da criança contra inúmeras infecções, evitando assim, que muitas mortes aconteçam. Estudos mostram que 830.000 crianças poderiam ser salvas todo 0 ano por meio do aleitamento ${ }^{(1)}$.

Ademais, pensar em práticas que garantam o aleitamento materno em serviços da atenção 
primária, como referido, neste estudo, vai ao encontro ao desafio lançado pela Estratégia Global para a Saúde de Mulheres, Crianças e Adolescentes (2016-2030), instaurada junto aos Objetivos de Desenvolvimento Sustentável, tendo o aleitamento como fator protetor capaz de reduzir inúmeras mortes evitáveis. As intenções e ações recíprocas ${ }^{(8)}$ de cuidado entre profissionais da saúde, comunidade e população materna e infantil, ou seja, todos lutando pela mesma causa, pode resultar em mais adesão ao aleitamento materno, chegando-se ao esperado e preconizado.

\section{CONSIDERAÇÕES FINAIS}

O grupo social formado por médicos e por enfermeiros participantes da pesquisa, possuem bagagem de conhecimento ainda incipiente sobre a adesão do aleitamento materno, em sua região, uma vez que, quando inquiridos diretamente sobre esses dados, os participantes da pesquisa relatam índices que provavelmente são sobreestimados, podendo-se inferir pouco conhecimento sobre dados reais da adesão do aleitamento materno em sua região. Para que esses profissionais tornem-se sensibilizados e conhecedores de sua realidade local, são necessárias práticas educativas que possibilitem instrumentalizá-los para o planejamento das ações recíprocas em saúde com a perspectiva de transformar os indicadores de morbimortalidade infantil.

As ações desenvolvidas por esses profissionais, para promover o aleitamento materno foram realizadas, pontualmente, em algum momento específico do pré-natal, puerpério ou durante o seguimento da criança, mostrando pouca oportunidade da relação face a face entre quem cuida e quem requer o cuidado. Tais ações ainda ocorrem de forma fragmentada, sendo fundamental reorganizar a assistência de forma que contemple a promoção do aleitamento, durante toda a assistência à díade mãe-filho. Além disso, as pesquisas apontam que se faz necessário chegar-se a subjetividade das mães que amamentam, conscientizando-as sobre a importância do aleitamento materno para si e para os seus filhos.

Os profissionais também relataram aspectos potencializadores e complicadores para o incentivo e manutenção do aleitamento, descrevendo o Programa Leite das Crianças que é uma realidade vivenciada no Estado.
Esperam que a saúde das crianças seja promovida e que a morbimortalidade, por causas evitáveis seja reduzida, através de ações propostas pela Rede Mãe Paranaense, as quais envolvem o incentivo e o auxílio ao aleitamento materno.

Embora este estudo apresente como limitação a impossibilidade de generalização dos resultados, uma vez que a especificidade da Rede não é adotada em todo o território brasileiro, fomenta possibilidades de reflexão sobre o tema, pois se coloca como introdução a novos debates, por considerar que o incentivo e o auxílio ao aleitamento materno se refere a uma ferramenta essencial para promoção da saúde infantil.

Entende-se que o estudo poderá contribuir para o ensino e pesquisa em saúde ao fornecer evidências sobre o conhecimento e fragilidades dos profissionais da atenção primária para a promoção do aleitamento materno. Ademais poderá amparar a tomada de decisão favorável com estratégias integradas e direcionadas para acrescer à prática da lactação, além de potencializar ações que subsidiem os médicos e enfermeiros no cotidiano profissional, ampliando a bagagem de conhecimento no tocante ao aleitamento materno.

\section{REFERÊNCIAS}

1- Victora CG, Bahhl R, Barros AJD, França GVA, Horton S, Kraseyec J, et al. Breastfeeding in the 21st century: Epidemiology, mechanisms, and lifelong effect. Lancet 2016;387(10017):475-90. DOI: 10.1016/S0140-6736(15)01024-7

2- World Health Organization (WHO). Implementation guidance: Protecting, promoting and supporting breastfeeding in facilities providing maternity and newborn services: the revised baby-friendly hospital initiative. Geneva: World Health Organization; 2018.

3- Boccolini CS, Boccolini PMM, Monteiro FR, Venâncio SI, Giuliani ERJ. Breastfeeding indicators trends in Brazil for three decades. Rev Saúde Pública 2017;51(108):1-9. DOI: 10.11606/S15188787.2017051000029

4- Teston EF, Reis TS, Góis LM, Spigolon DN, Maran E, Marcon SS. Aleitamento materno: Percepção do pai sobre seu papel. Rev Enferm Cent-Oeste Min. 2018;8:1-7. DOI: 10.19175/recom.v8i0.2723

5- Teles MAB, Silva Junior RRF, Santos Junior GG, Fonseca MP, Eugênio KK. Knowledge and practices of breastfeeding of users from the family health strategy. Rev Enferm UFPE 
2017;11(6):2302-8. DOI: 10.5205/reuol.1082796111-1-ED.1106201707

6- Toryama ATM, Fujimori E, Palombo CNT, Duarte LS, Borges AL, Chofakian CBN. Breastfeeding: What changed after a decade? Rev Latino-Am Enfermagem 2017;25:1-10. DOI: 10.1590/1518-8345.1858.2941

7- Secretaria de Estado da Saúde do Paraná (SESA/PR). Linha guia: Programa Rede Mãe Paranaense. Curitiba (PR): Secretaria de Estado da Saúde do Paraná; 2017.

8- Schütz A. Sobre fenomenologia e relações sociais. Petrópolis: Vozes; 2012.

9- Caldeira S, Bugs TV, Machineski GG, Fiewski MFC, Bugs BM, Tacla MTGM, et al. Percepção, conhecimento e atuação dos médicos no programa rede mãe paranaense. Saúde 2016;42(2):185-94. DOI:

\section{$10.5902 / 2236583419576$}

10- Rocci E, Fernandes RAQ. Breastfeeding difficulties and influence in the early weaning. Rev Bras Enferm. 2014; 67(1):22-7. DOI: doi.org/10.5935/0034-7167.20140002

11- Linhares FMP, Pontes CM, Osorio MM. Construtos teóricos de Paulo Freire norteando as estratégias de promoção à amamentação. Rev Bras Saude Mater Infant. 2014;14(4):433-9. DOI: 10.1590/S1519-38292014000400013

12- Ghaffari M, Rakhshanderou S, Mehrabi Y, Tizvir A. Using social network of telegram for education on continued breastfeeding and complementary feeding of children among mothers: a successful experience from Iran. Int J Pediatr Nephrol 2017;5(7):5275-86. DOI: 10.22038/IJP.2017.22849.1915

13- Urbanetto PDG, Gomes GC, Costa AR, Nobre CMG, Xavier DM, Jung BC. Facilities and difficulties found by mothers to breastfeed. Rev Pesq Cuid Fundam 2018;10(2):399-405. DOI: 10.9789/2175-5361.2018.v10i2

14- Amaral LJX, Sales SS, Carvalho DPSRP, Cruz GKP, Azevedo ICA, Ferreira Junior MA. Factors that influence the interruption of exclusive breastfeeding in nursing mothers. Rev Gaúcha Enferm. 2015;36(nesp):127-34. DOI: 10.1590/1983-1447.2015.esp.56676

15- Monteiro FR, Buccini GS, Venâncio SI, Costa THM. Influence of maternity leave on exclusive breastfeeding. J Pediatr. 2017;93(5):475-81. DOI: 10.1016/i.jped.2016.11.016

16- Santos APR, Santos GA, Siqueira SMC. Ações desencadeadas pelo enfermeiro para promoção do aleitamento materno e prevenção do desmame precoce. REBRASF2017 [citado em 20 mar 2019]; 1(1):56-65. Available in: http://www.seer-

adventista.com.br/ojs/index.php/RBSF/article/vie $\mathrm{w} / 815 / 674$

17- Jefferson UT. Predictors of breastfeeding attitudes among college-educated African Americans. Res Theory Nurs Pract. 2015;29(3):189-99. DOI: $10.1891 / 1541-$ 6577.29.3.189

18- Secretaria da Agricultura e do Abastecimento (PR). Comissão Estadual da Qualidade do Leite CEQL. Curitiba (PR): Secretaria da Agricultura e do Abastecimento; 2003 [citado em 21 mar 2019]. Available

in: http://www.leitedascriancas.pr.gov.br/modules/c onteudo/conteudo.php?conteudo $=35$

19- Saldan PC, Venâncio SI, Saldiva SRDM, Vieira DG, Mello DF. Milk consumption in infants under one year of age and variables associated with non-maternal milk consumption. Rev Paul Pediatr. 2017;35(4):407-14. DOI: 10.1590/19840462/;2017;35;4;00004

20- Oliveira SC, Locca FA, Carrijo MLR, Garcia RAT. Breastfeeding and complications that contribute to early weaning. Rev Gaúcha Enferm. 2015;36(nesp):16-23. DOI: 10.1590/1983$\underline{1447.2015 . e s p .56766}$

Nota: Financiamento Capes.

Recebido em: 04/04/2019

Aprovado em: 23/09/2019

Endereço de correspondência:

Rosane M. M. da Silva

Av. Tarquínio J. dos Santos, 1300, Jardim Universitário. CEP: 85870-650 - Foz do Iguaçu/PR - Brasil

E-mail: zanem2010@hotmail.com 